Article

\title{
Facile and Convenient One-Pot Process for the Synthesis of Spirooxindole Derivatives in High Optical Purity Using $(-)-(S)$-Brevicolline as an Organocatalyst
}

\section{Fliur Macaev *, Natalia Sucman, Felix Shepeli, Marina Zveaghintseva and Vsevolod Pogrebnoi}

Academy Street 3, Institute of Chemistry, Academy of Science of Moldova, MD-2028 Chisinau, Moldova; E-Mails: nicheli@yandex.ru (N.S.); dianashepel@mail.ru (F.S.); mari6azv@ mail.ru (M.Z.); seva.antivirus@gmail.com (V.P.)

* Author to whom correspondence should be addressed; E-Mail: flmacaev@cc.acad.md;

Tel.: +373-22-73-97-54; Fax: +737-22-73-99-54.

Received: 10 March 2011; in revised form: 11 April 2011 / Accepted: 12 April 2011 /

Published: 20 April 2011

\begin{abstract}
The paper presents an application of the asymmetry approach to spirooxindoles via Brevicolline, Cinchonidine or Cinchonine catalyzed one-pot multicomponent synthesis. Brevicolline, in comparison with Cinchonidine or Cinchonine, catalyzes the reaction of isatins, acetylacetone/ethyl 3-oxobutanoate and malononitrile, with the formation of spiro[oxindole-3,4'-4' $H$-pirane] derivatives in an optically active form in very good to excellent yields.
\end{abstract}

Keywords: organocatalyzed reactions; spiro[oxindole-3,4'-4'H-pyrane]; Brevicolline; Cinchonidine; Cinchonine

\section{Introduction}

Asymmetric catalysis with the participation of organic compounds is one of the most rapidly developing areas of modern chemistry [1-5]. A special position among these catalysts is occupied by alkaloids, with the vast majority of research, until recently, being focused on the discovery of new properties of the well-studied cinchona alkaloids and related compounds [6-11]. The cupreine-catalyzed synthesis of optically active spiro[pyran-oxindoles] as promising candidates for chemical biology and drug discovery has been reported recently [12]. This important trend towards obtaining 
single-enantiomer drugs has brought the asymmetric synthesis to the forefront. Nowadays it has become an important subject in drug discovery and development [13].

\section{Results and Discussion}

In this paper we report an application of the alkaloids Cinchonidine 1a, Cinchonine $\mathbf{1 b}$ and Brevicolline 1c (see Figure 1) as new catalysts to a known synthesis of spiro[oxindole-3,4'-4' $H$-pyrane] derivatives 5a,b,c [12].

Our initial studies were performed only on catalysts Cinchonidine 1a and Cinchonine $\mathbf{1 b}$ because related $C^{\sigma^{\prime}}-\mathrm{OH}$ cinchona alkaloids were used by Wei-Cheng Yuan et al. [12] for organocatalytic studies in the reaction of $\mathrm{N}$-substituted isatines, acetylacetone and malononitrile.

Figure 1. Catalysts used in this study.

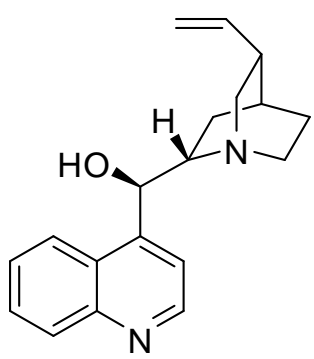

a

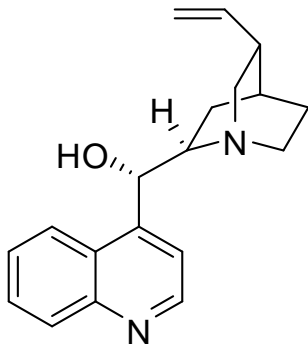

$\mathrm{b}$

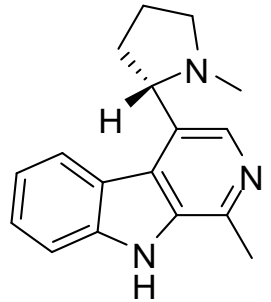

C

The presence of water in the reaction media (after forming isatylidene malononitrile) at room temperature had a negative effect on the enantioselectivity for the spirane 5a (see Scheme 1). Finally, the reaction of $\mathrm{N}$-Bn isatine 2a carried out in dichloromethane (DCM) as a solvent using $10 \mathrm{~mol} \%$ of $\mathbf{1 a}$ as catalyst at room temperature (rt) gave a spirane 5a with $85 \%$ yield, but low enantioselectivity $(2 \% e e)$.

Scheme 1. One-pot multicomponent synthesis.

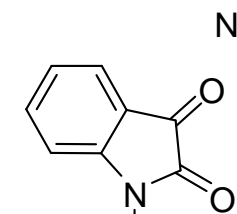

$\mathrm{R}^{1}$

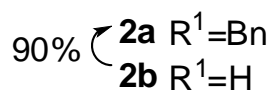

Cat 1a-c (10 mol \%) $\mathrm{DCM}, 4 \mathrm{~A} \mathrm{MS}, 0^{\circ} \mathrm{C}$

$50-98 \%$

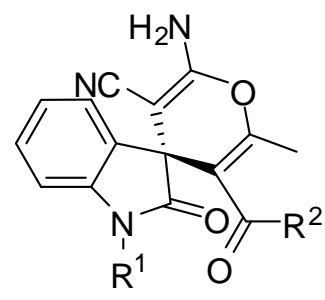

5a $R^{1}=B n, R^{2}=M e$

$5 \mathrm{~b} \mathrm{R}^{1}=\mathrm{Bn}, \mathrm{R}^{2}=\mathrm{OEt}$

5c $\mathrm{R}^{1}=\mathrm{H}, \quad \mathrm{R}^{2}=\mathrm{Me}$

When the temperature was decreased to $0{ }^{\circ} \mathrm{C}$ in the presence of the freshly activated $4 \AA$ MS, the spirane 5a was obtained with $80 \%$ yield and $23 \%$ ee (Table 1, entry 1 ). However, the use of $\mathbf{1 b}$ as a catalyst at $\mathrm{rt}$ gave the results practically similar to those as with the use of $\mathbf{1 a}$. The $\%$ ee's was also confirmed by HPLC using Chiralpak IA column. (Table 1, entry 2). 
Table 1. Scope of one-pot multicomponent synthesis of spiro[oxindole-3,4'-4'H-pyrane] derivatives.

\begin{tabular}{cccccccc}
\hline Entry & Catalyst & Isatine & Dicarbonyl compound & Product & ${ }^{\mathrm{a}}$ Yield $(\boldsymbol{\%})$ & {$[\boldsymbol{\alpha}]_{\mathbf{D}}$} & ${ }^{\mathbf{b} / \mathbf{c} e \boldsymbol{e}(\boldsymbol{\%})}$ \\
\hline 1 & $\mathbf{1 a}$ & $\mathbf{2 a}$ & $\mathbf{4 a}$ & $\mathbf{5 a}$ & 80 & $+2(c 0.35)$ & ${ }^{\mathrm{b}} 23$ \\
2 & $\mathbf{1 b}$ & $\mathbf{2 a}$ & $\mathbf{4 a}$ & $\mathbf{5 a}$ & 77 & $+1.8(c 0.84)$ & ${ }^{\mathrm{b}} 21 /$ \\
& & & & & & & ${ }^{\mathrm{e}} 15$ \\
3 & $\mathbf{1 c}$ & $\mathbf{2 a}$ & $\mathbf{4 a}$ & $\mathbf{5 a}$ & 50 & $+3.7(c 0.6)$ & ${ }^{\mathrm{b}} 43$ \\
4 & $\mathbf{1 a}$ & $\mathbf{2 a}$ & $\mathbf{4 b}$ & $\mathbf{5 b}$ & 87 & $+2.27(c 0.9)$ & ${ }^{\mathrm{c}} 8$ \\
5 & $\mathbf{1 b}$ & $\mathbf{2 a}$ & $\mathbf{4 b}$ & $\mathbf{5 b}$ & 98 & $+0.98(c 1.16)$ & ${ }^{\mathrm{c}} 3$ \\
6 & $\mathbf{1 c}$ & $\mathbf{2 a}$ & $\mathbf{4 b}$ & $\mathbf{5 b}$ & 68 & $+3.5(c 0.33)$ & ${ }^{\mathrm{c}} 12$ \\
7 & $\mathbf{1 a}$ & $\mathbf{2 b}$ & $\mathbf{4 a}$ & $\mathbf{5 c}$ & 60 & $+6.32(c 0.17)$ & ${ }^{\mathrm{d}} 22$ \\
8 & $\mathbf{1 b}$ & $\mathbf{2 b}$ & $\mathbf{4 a}$ & $\mathbf{5 c}$ & 67 & $+2.16(c 0.35)$ & ${ }^{\mathrm{e}} 8$ \\
9 & $\mathbf{1 c}$ & $\mathbf{2 b}$ & $\mathbf{4 a}$ & $\mathbf{5 c}$ & 62 & $+46.8(c 0.12)$ & ${ }^{\mathrm{e}} 94$ \\
\hline
\end{tabular}

${ }^{\mathrm{a}}$ Of the isolated products after column chromatography; ${ }^{\mathrm{b}}$ Based on the specific rotation measured using Jasco-P-2000 polarimeter compared with $[\alpha]_{\mathrm{D}}=+8.1(c 0.37 \mathrm{MeOH}) ; e e=94 \%[12]$; ${ }^{c}$ Based on the specific rotation measured using Jasco-P-2000 polarimeter compared with $[\alpha]_{\mathrm{D}}=+21.3(c 0.14 \mathrm{MeOH})$; $e e=74 \%[12] ;{ }^{\mathrm{d}}$ Based on the specific rotation measured using Jasco-P-2000 polarimeter compared with $[\alpha]_{\mathrm{D}}=+21.0(c 0.15 \mathrm{MeOH}) ; e e=78 \%$ [12]; ${ }^{\mathrm{e}}$ The $e e$ measurement was confirmed by HPLC using Chiralpak IA column; $i$-propanol $/$ hexane $=10 / 90$, flow rate $1.0 \mathrm{~mL} / \mathrm{min}, \lambda=254 \mathrm{~nm}, t R$ (major) $=19.25 \mathrm{~min}$, $t R($ minor $)=25.26 \mathrm{~min}$.

We envisioned that Brevicolline 1c (see Figure 1) could be also useful for such catalytic processes. $(S)$-Brevicolline possessing the core of $(S)$-nicotine structure was isolated by us from the plant Carex brevicollis DC (Cyperacee). ${ }^{1} \mathrm{H}$ NMR, and IR data of our alkaloid match exactly with those reported earlier for 1c [14-16]. The melting point and optical rotation, however, differ slightly from literature data. A higher melting point $\left(232-233{ }^{\circ} \mathrm{C}\right.$ instead of $\left.223-224{ }^{\circ} \mathrm{C}\right)$ and an increased $[\alpha]_{20} \mathrm{D}(-154.16$ instead of -145.8$)$ indicate higher purity. The $100 \%$ ee measurement was confirmed by HPLC [17].

When we were working with Brevicolline 1c at $0{ }^{\circ} \mathrm{C}$ in DCM, the reaction time for 5a increased and the yield was lower (50\%), however the enantioselectivities were slightly higher than those obtained using 1a, b (Table 1, compare entries 1, 2 and 3).

When we increased the molar ratio up to 50 mol\% of catalysts 1a-c, but kept the amount of $4 \AA$ MS as well as temperature $0{ }^{\circ} \mathrm{C}$ constant, only a small change in $\%$ ee towards an increase was observed. Therefore, the rest of the investigation was carried out with 10 mol\% of catalysts $1 a-c$.

Further, we studied the influence of the ethyl acetoacetate as nucleophilic component on the selectivity of the reaction $N$-Bn isatine $2 \mathbf{a}$ with malononitrile.

In all the tested cases the product $\mathbf{5 b}$ was obtained with very good to excellent yields (Table 1 , entries 4, 5 and 6). Slightly higher enantioselectivity has been observed in the reaction between $N$-Bn isatine, ethyl acetoacetate, and malononitrile using 1c as a catalyst than in the reaction with catalysts $\mathbf{1 a}, \mathbf{b}$.

The effect of the unprotected isatine $\mathbf{2} \mathbf{b}$ in the enantiochemical outcome of the reaction was studied. Entries 7-9 in Table show the addition of malononitrile together with acetylacetone to isatine $\mathbf{2} \mathbf{b}$ in the presence of Cinchonidine, Cinchonine or Brevicolline, respectively.

In the cases of Cinchonidine and Cinchonine, good conversions (up to 67\%), but low enantioselectivities were obtained. 
The highest enantiomeric excess (based on the specific rotation $[\alpha]_{20}{ }^{\mathrm{D}}=+46.8$ compared with $[\alpha]_{20}{ }^{\mathrm{D}}=+21.0 ; e e=78 \%$ [12]) was obtained for product $\mathbf{5 c}$ when Brevicolline $\mathbf{1 c}$ was used as catalyst. The $94 \%$ ee measurement was confirmed by HPLC using Chiralpak IA.

At this point, the distinguishing features of the active species inducing chirality are not understood. However, we believe that the induced chirality is due to the intermolecular cycloaddition involving hydrogen-bonding interactions of the $\mathrm{CN}$ group with chiral $\mathrm{N}$-methylpyrrolidinyl core as well as keto-enol tautomerism equilibrium via the interaction with the $\mathrm{NH}$ group [18]. This creates a chiral pocket which influences the selectivity of $\beta$-dicarbonyl group transfer from acetylacetone/ethyl 3 -oxobutanoate to isatylidene malononitrile derivatives. Tracer experiments to clarify the mechanisms and further studies on the reactivity of Brevicolline as organocatalyst are in progress.

We have also observed that all catalysts $\mathbf{1 a}-\mathbf{c}$ can be recovered during the isolation of products $\mathbf{5 a}-\mathbf{c}$.

\section{Experimental}

\subsection{General Data}

Solvents and commercially available reagents were purchased from Aldrich (Germany), Across (Belgium) and Lancaster (Great Britain). Brevicolline was extracted from Carex brevicollis and purified by crystallization according to [14-16]. Dichloromethane was dried and distilled before using. The molecular sieves have been heated up to $180{ }^{\circ} \mathrm{C}$ for two hours. Thin-layer chromatography was carried out on Merck aluminum sheets, silica gel $60 \mathrm{~F}_{254}$. Column chromatography was performed on Fluka silica gel 60, 70-230 mesh. Melting points were determined on a Boëtius melting point apparatus (PHMK, VEB Wägetechnik Rapido, Radebeul, Germany) and are uncorrected. ${ }^{1} \mathrm{H}$ - and ${ }^{13} \mathrm{C}-\mathrm{NMR}$ spectra were recorded on a Bruker Avance III 400 spectrometer operating at $400.13 \mathrm{MHz}$ for ${ }^{1} \mathrm{H}$ and $100.61 \mathrm{MHz}$ for ${ }^{13} \mathrm{C}$. Chemical shifts $\delta$ are given in ppm referring to the signal center using the solvent peaks for reference: DMSO- $\mathrm{d}_{6} 2.50 \mathrm{ppm} / 39.52 \mathrm{ppm}$. The NMR signals were assigned by two-dimensional ${ }^{1} \mathrm{H},{ }^{1} \mathrm{H}$ COSY and ${ }^{1} \mathrm{H},{ }^{13} \mathrm{C}$ correlation spectra (HSQC, HMBC) using standard pulse sequences. IR spectra were recorded on apparatus "Perkin-Elmer Spectrum 100 FTIR". The specific rotation has been recorded on "Jasco-P-2000" in $\mathrm{MeOH}$.

\subsection{General Procedure for Preparing of Compounds (5)}

Malononitrile $(0.89 \mathrm{mmol})$, catalyst $(10 \mathrm{~mol} \%)$ and molecular sieves to the suspension of the corresponding oxindoles $(0.89 \mathrm{mmol})$ in dry DCM $(4 \mathrm{~mL})$ were added at vigorous stirring. The reaction mixture was put into the ice bath and after cooling acetylacetone (or ethyl acetoacetate) was added. After six hours of stirring at $0{ }^{\circ} \mathrm{C}$ (monitored by TLC) the solvent was evaporated and the residue was purified by column chromatography ( $\mathrm{DCM} / \mathrm{MeOH} 0-2 \%)$.

5'-Acetyl-2'-amino-6'-methyl-spiro[oxindole-3,4'-4'H-pyran]-3'carbonitrile (5a)

M.p. 249-252 ${ }^{\circ} \mathrm{C}(\mathrm{MeOH}) ;{ }^{1} \mathrm{H}-\mathrm{NMR}\left(\mathrm{DMSO}_{6}\right) \delta 2.09\left(\mathrm{~s}, 3 \mathrm{H}, \mathrm{CCH}_{3}\right), 2.29\left(\mathrm{~s}, 3 \mathrm{H}, \mathrm{COCH}_{3}\right)$, $6.78(\mathrm{~d}, 1 \mathrm{H}, J=8.0 \mathrm{~Hz}, H$ ind), 6.92 (td, $1 \mathrm{H}, J=8.0,2.0 \mathrm{~Hz}, H$ ind), 7.04 (d, 1H, $J=8.0 \mathrm{~Hz}, H$ ind), $7.12\left(\mathrm{~s}, 2 \mathrm{H}, \mathrm{NH}_{2}\right), 7.16(\mathrm{td}, 1 \mathrm{H}, J=8.0,2.0 \mathrm{~Hz}, H \mathrm{ind}), 10.39(\mathrm{~s}, 1 \mathrm{H}, \mathrm{NH}) ;{ }^{13} \mathrm{C}-\mathrm{NMR}\left(\mathrm{DMSO}-\mathrm{d}_{6}\right)$ $\delta 19.71\left(\mathrm{CCH}_{3}\right), 31.68\left(\mathrm{COCH}_{3}\right), 49.90\left(C^{3}\right), 57.31(\mathrm{CCN}), 109.91(C \mathrm{Hind}), 115.32\left(\mathrm{CCH}_{3}\right)$, 
$117.92(C \mathrm{~N}), 122.32$ (CHind), 123.86(CHind), 128.98 (CHind), 134.48 (Cind), 142.45 (Cind), $156.30\left(C^{6^{\prime}}\right), 159.75\left(\mathrm{CNH}_{2}\right), 178.88(\mathrm{CONH}), 197.97\left(\mathrm{COCH}_{3}\right) ; \mathrm{IR} \mathrm{cm}{ }^{-1} 3376.8,3343.4\left(\mathrm{NH}_{2}\right)$, $3113.0(\mathrm{NH}), 2187.1(\mathrm{CN}), 1706.0(\mathrm{CONH}), 1679.1(\mathrm{CO})$.

5'-Acetyl-2'-amino-1-benzyl-6'-methyl-spiro[oxindole-3,4'-4'H-pyran]-3'carbonitrile (5b)

M.p. $209{ }^{\circ} \mathrm{C}$ (sub), $229{ }^{\circ} \mathrm{C}(\mathrm{dec})(\mathrm{DCM} / \mathrm{MeOH}) ;{ }^{1} \mathrm{H}-\mathrm{NMR}\left(\mathrm{DMSO}_{6} \mathrm{~d}_{6}\right) \delta 2.12\left(\mathrm{~s}, 3 \mathrm{H}, \mathrm{CCH}_{3}\right)$, $2.37\left(\mathrm{~s}, 3 \mathrm{H}, \mathrm{COCH}_{3}\right), 4.86(\mathrm{~d}, 1 \mathrm{H}, J=16.0 \mathrm{~Hz}, \mathrm{CH} H \mathrm{~N}), 4.95(\mathrm{~d}, 1 \mathrm{H}, J=16.0 \mathrm{~Hz}, \mathrm{CH} H \mathrm{~N})$, 6.69 (d, 1H, $J=7.6 \mathrm{~Hz}$, Hind), 6.99 (t, 1H, $J=7.4, \mathrm{~Hz}$, Hind), 7.09-7.16 (m, 4H, NH , Hind,), 7.24-7.33 (m, 3H, HAr), 7.47 (d, 2H, $J=7.4 \mathrm{~Hz}, H A r) ;{ }^{13} \mathrm{C}-\mathrm{NMR}\left(\mathrm{DMSO}_{\mathrm{d}}\right) \delta 19.93\left(\mathrm{CCH}_{3}\right), 31.72$ $\left(\mathrm{COCH}_{3}\right), 44.00\left(\mathrm{CH}_{2}\right), 49.52\left(C^{3}\right), 57.09(\mathrm{CCN}), 109.38(C \mathrm{Hind}), 115.32\left(\mathrm{CCH}_{3}\right), 117.78(C \mathrm{~N})$, 122.92 (CHind), 123.51 (CHind), 127.48 (CAr), 127.59 (CHAr), 128.72 (CHAr), 128.82 (CAr), 133.76 (CHind), 136.42 (Cind), 143.10 (Cind), $156.76\left(C^{6}\right), 159.76\left(\mathrm{CNH}_{2}\right), 177.42(C \mathrm{ONH}), 197.32$ $\left(\mathrm{COCH}_{3}\right)$; IR cm ${ }^{-1} 3361.3,3292.6\left(\mathrm{NH}_{2}\right), 3144.4(\mathrm{NH}), 2192.6(\mathrm{CN}), 1709.1(\mathrm{CONH}), 1676.2(\mathrm{CO})$.

Ethyl 6'-amino-1-benzyl-5'-cyano-2'-methyl-spiro[oxindole-3,4'-4'H-pyran]-3'carboxylate (5c)

M.p. $204{ }^{\circ} \mathrm{C}$ (sub), $222{ }^{\circ} \mathrm{C}(\mathrm{dec})(\mathrm{DCM} / \mathrm{MeOH}) ;{ }^{1} \mathrm{H}-\mathrm{NMR}\left(\mathrm{DMSO}-\mathrm{d}_{6}\right) \delta 0.58(\mathrm{t}, 3 \mathrm{H}, J=7.0 \mathrm{~Hz}$, $\left.\mathrm{CH}_{2} \mathrm{CH}_{3}\right), 2.34\left(\mathrm{~s}, 3 \mathrm{H}, \mathrm{COCH}_{3}\right), 3.51-3.55\left(\mathrm{~m}, 1 \mathrm{H}, \mathrm{CHHCH}_{3}\right), 3.77-3.81\left(\mathrm{~m}, 1 \mathrm{H}, \mathrm{CHHCH}_{3}\right)$, $4.78(\mathrm{~d}, 1 \mathrm{H}, J=15.8 \mathrm{~Hz}, \mathrm{CH} H \mathrm{~N}), 5.01(\mathrm{~d}, 1 \mathrm{H}, J=15.8 \mathrm{~Hz}, \mathrm{CH} H \mathrm{~N}), 6.86(\mathrm{~d}, 1 \mathrm{H}, J=7.8 \mathrm{~Hz}, H$ ind $)$, 7.02 (t, 1H, $J=7.4, \mathrm{~Hz}$, Hind), 7.16 (d, 1H, $J=6.8 \mathrm{~Hz}$, Hind), 7.21 (t, 1H, $J=7.6, \mathrm{~Hz}$, Hind), 7.26 $\left(\mathrm{s}, 2 \mathrm{H}, \mathrm{NH}_{2}\right), 7.27-7.34(\mathrm{~m}, 3 \mathrm{H}, H \mathrm{Ar}), 7.47(\mathrm{~d}, 2 \mathrm{H}, J=7.0 \mathrm{~Hz}, H \mathrm{Ar}) ;{ }^{13} \mathrm{C}-\mathrm{NMR}\left(\mathrm{DMSO}_{-} \mathrm{d}_{6}\right) \delta 13.56$ $\left(\mathrm{CH}_{2} \mathrm{CH}_{3}\right), 19.12\left(\mathrm{CCH}_{3}\right), 43.90\left(\mathrm{NCH}_{2}\right), 49.03\left(\mathrm{C}^{3}\right), 56.72(\mathrm{CCN}), 60.58\left(\mathrm{CH}_{2} \mathrm{CH}_{3}\right), 105.07\left(\mathrm{CCH}_{3}\right)$, 109.38 (CHind), $117.98(C \mathrm{~N}), 123.19$ (CHind), 123.80 (CHind), 127.81 (CAr), 128.00 (CHAr), 128.86 (CHAr), 129.12 (CAr), 134.12 (CHind), 136.64 (Cind), 143.24 (Cind), $159.30 \quad\left(C^{6}\right)$, $159.68\left(\mathrm{CNH}_{2}\right), 164.85\left(\mathrm{COCH}_{2}\right), 177.42(\mathrm{CONH}) ; \mathrm{IR} \mathrm{cm}{ }^{-1} 3377.9,3246.5\left(\mathrm{NH}_{2}\right), 3187.3(\mathrm{NH})$, $2193.1(\mathrm{CN}), 1710.3(\mathrm{CONH}), 1665.5(\mathrm{CO})$.

\section{Conclusions}

We have demonstrated that Brevicolline, Cinchonidine and Cinchonine can be used as organocatalysts to achieve asymmetric induction in one-pot multicomponent synthesis of spiro [oxindole-3,4'-4' $H$-pyrane] derivatives. Although currently the enantioselectivity obtained is moderate to good, several important parameters have been studied. The useful insight into the understanding of the application of Brevicolline, Cinchonidine and Cinchonine has led to the "design" of other inductors, which can afford higher enantioselectivities. The results of these studies will be reported in the near future.

\section{Acknowledgements}

The authors (F.M. and N.S.) gratefully acknowledge generous financial support from the Royal Society International Joint Project 2009-2011(Ref. No. JP090309). 


\section{References and Notes}

1. Berkessel, A.; Gröger, H. Asymmetric Organocatalysis: From Biomimetic Concepts to Applications in Asymmetric Synthesis; Wiley-VCH: Baden-Württemberg, Germany, 2005; p. 440.

2. Dondoni, A.; Massi, A. Asymmetric Organocatalysis: From Infancy to Adolescence. Angew. Chem. Int. Ed. 2008, 47, 4638-4660.

3. Carlos, F.B., III. Organocatalysis Lost: Modern Chemistry, Ancient Chemistry, and an Unseen Biosynthetic Apparatus. Angew. Chem. Int. Ed. 2007, 47, 42-47.

4. Dalko, P.I.; Moisan, L. In the Golden Age of Organocatalysis. Angew. Chem. Int. Ed. 2004, 43, 5138-5175.

5. Melchiorre, P.; Marigo, M.; Carlone, A.; Bartoli, G. Asymmetric Aminocatalysis-Gold Rush in Organic Chemistry. Angew. Chem. Int. Ed. 2008, 47, 6138-6171.

6. Nie, J.; Guo, H.-C.; Cahard, D.; Ma, J.-A. Asymmetric Construction of Stereogenic Carbon Centers Featuring a Trifluoromethyl Group from Prochiral Trifluoromethylated Substrates. Chem. Rev. 2011, 111, 455-529.

7. Zhao, W. Novel Syntheses of Bridge-Containing Organic Compounds. Chem. Rev. 2010, 110, 1706-1745.

8. Kizirian, J.-C. Chiral Tertiary Diamines in Asymmetric Synthesis. Chem. Rev. 2008, 108, 140-205.

9. France, S.; Guerin, D.J.; Miller, S.J.; Lectka, T. Nucleophilic Chiral Amines as Catalysts in Asymmetric Synthesis. Chem. Rev. 2003, 103, 2985-3012.

10. Doyle, A.G.; Jacobsen, E.N. Small-Molecule H-Bond Donors in Asymmetric Catalysis. Chem. Rev. 2007, 107, 5713-5743.

11. Marcelli, T.; van Maarseveen, J.H.; Hiemstra, H. Cupreines and Cupreidines: An Emerging Class of Bifunctional Cinchona Organocatalysts. Angew. Chem. Int. Ed. 2006, 45, 7496-7504.

12. Chen, W.-B.; Wu, Z.-J.; Pei, Q.-L.; Cun, L.-F.; Zhang, X.-M.; Yuan, W.-C. Highly enantioselective construction of spiro [4H-pyran-3,3'-oxindoles] through a domino Knoevenagel/Michael/Cyclization sequence catalyzed by cupreine. Org. Lett. 2010, 12, 3132-3135.

13. Farina, V.; Reeves, J.T.; Senanayake, C.H.; Song, J.J. Asymmetric Synthesis of Active Pharmaceutical Ingredients. Chem. Rev. 2006, 106, 2734-2793.

14. Vember, P.A.; Terenteva, I.V.; Lazurevskij, G. The structure of brevikolline. Khim. Prir. Soedin. 1967, 3, 249.

15. Terenteva, I.V.; Lazurevskij, G.V.; Shirshova, T.I. About the structure of brevikarine. Khim. Prir. Soedin. 1969, 5, 397.

16. Vember, P.A.; Terenteva, I.V.; Uljanova, A.V. About the structure of brevikolline. Khim. Prir. Soedin. 1968, 4, 98.

17. The ee measurement was confirmed by HPLC using Chiralpak IA $[n$-hexane/ $i$-PrOH $=80 / 20$, $1.0 \mathrm{~mL} / \mathrm{min}, t=5.536 \mathrm{~min}]$.

18. Gaunt, M.J.; Johansson, C.C. Recent Developments in the Use of Catalytic Asymmetric Ammonium Enolates in Chemical Synthesis. Chem. Rev. 2007, 107, 5596-5605.

(C) 2011 by the authors; licensee MDPI, Basel, Switzerland. This article is an open access article distributed under the terms and conditions of the Creative Commons Attribution license (http://creativecommons.org/licenses/by/3.0/). 